\title{
Cigarette smoke exposure inhibit antibody production via inhibition of alveolar macrophage
}

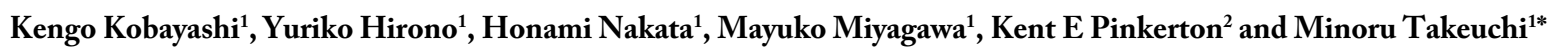 \\ ${ }^{1}$ Department of Animal Medical Science, Faculty of Life Science, Kyoto Sangyo University, Motoyama, Kamigamo, Kita-ku, Kyoto 603-8555, Japan \\ ${ }^{2}$ Center for Health and the Environment, University of California Davis, Davis, CA95616, USA
}

\begin{abstract}
Introduction: Alveolar macrophages (AM) play an important role in the immune system of the lung. Cigarette smoke (CS) is known to suppress antibody production, but the related mechanism with AM is not clearly understood. The aim of this study was to investigate how CS affects antibody production through alveolar macrophage.

Methods: Mice were exposed to 20 cigarettes/day for 10 days. AM were obtained by broncho - alveolar lavage. Antibody production was analyzed by plaque forming cell assay using sheep red blood cells (SRBC) as antigen. B cell proliferation was analyzed by ${ }^{3} \mathrm{H}$-thymidine incorporation. Phagocytic activity using fluorescein isothiocyanate labeled SRBC and expression of surface antigens on AM were analyzed by flow cytometry. Cytokines and NF- $\mathrm{BB}$ mRNA expression of AM were analyzed by RT-PCR.

Results: Antibody production was decreased at the induction phase, but not the expression phase by AM from mice exposed to CS compared with mice not exposed to CS. Cell surface antigens of Class II and CD80 on AM was decreased in mice exposed to CS compared with mice not exposed to CS. Phagocytoic activity, and cytokine/NF- $\kappa \mathrm{B}$ mRNA expression of AM were decreased in mice exposed to CS compared with mice not exposed to CS.
\end{abstract}

Conclusion: These results suggest that the inhibition of antibody production by cigarette smoke is caused by the inhibition of phagocytosis and expression of surface antigens associated with antigen presentation. Such inhibition of AM functions may increase the risk of bacterial and virus infections such as COVID-19.

\section{Introduction}

Cigarette smoke (CS) consists of mainstream smoke, sidestream smoke, growing smoke, diffusion smoke, effusion smoke, smoldering smoke and blowing smoke, which are exhaled by a smoker [1,2]. CS, except for mainstream smoke, is called environmental tobacco smoke (ETS) [2]. Approximately 6,000 different chemicals are found in CS, and 200 of these are considered as toxic substances [3]. CS has a gas phase and a particle phase. Carbon monoxide and ammonia are part of the gas phase. The particle phase includes nicotine and benzopyrene. CS includes many kinds of carcinogen and cancer promoters [2,4]. Cigarette smoking, a major risk factor for development of cancer, has also been associated with an increased incidence of infections, chronic pulmonary obstructive disease (COPD), asthma and bronchitis $[5,6]$.

The gas exchange area of the lung consists of alveoli where alveolar macrophages play an important role in lung immunity [7]. Functions of AM are mainly phagocytosis; production of cytokines, enzymes and reactive oxygen intermediates; and antigen presentation $[8,9]$. When CS reaches the alveoli, it is recognized and incorporated by AM as a foreign substance. Therefore, CS may affect AM functions and a number of immune responses.

Various studies concerning the effect of the immune system by cigarette smoking have been reported from the 1970's. There are reports that the number of leukocytes are increased in smokers as well as in humans and mice [10]. AM have reduced phagocytosis, antigen presentation, and production of inflammatory cytokines $[4,5,9]$. In addition, there are reports that proliferation of spleen lymphocytes and antibody production are reduced by cigarette smoking [11,12].
However, there is no consensus on the effect of CS on the immune function.

In previous studies, we demonstrated that the cigarette smoking induces functional changes in AM [13-17]. However, the mechanism of immune suppression associated with AM by CS is not clearly understood. Therefore, we investigated the effects of CS on antibody production, phagocytosis, surface antigen expression and mRNA expression associated with immune function of AM.

\section{Materials and methods}

\section{Animals}

C57BL/6 female mice were purchased from Japan SLC, Inc. (Shizuoka, Japan). The mice were housed in transparent plastic cages with stainless wire lids in the animal facility of Kyoto Sangyo University (Kyoto, Japan) under standard conditions, with a dark period from $8 \mathrm{pm}$ to $8 \mathrm{am}$, and water and food were provided ad libitum. All mice were between 8 to 10 weeks of age. This study was

${ }^{*}$ Correspondence to: Minoru Takeuchi, DVM, PhD, Professor, Department of Animal Medical Science, Faculty of Life Science, Kyoto Sangyo University, Motoyama, Kamigamo, Kita-ku, Kyoto 603-8555, Japan, E-mail: mtakex@ cc.kyoto-su.ac.jp

Key words: cigarette smoke, alveolar macrophage, phagocytosis, antibody production, antigen presentation

Received: July 09, 2020; Accepted: July 20, 2020; Published: July 23, 2020 
approved by the committee for animal use and care at Kyoto Sangyo University.

\section{Cigarette smoke (CS) exposure}

Mice in the CS group were exposed to main stream smoke from 20 filter-tipped cigarettes (Reference Cigarette CORESTA APPROVED MONITOR No.5) per day during 10 days using a Hamburg II smoking machine (Leybold- Heraeus, Hamburg, Germany). CS was diluted with air at a ratio of $7: 3$, and the puff volume was $35 \mathrm{ml} / 2 \mathrm{sec} / 1$ puff. Mice in the non-CS group were treated under identical conditions as the CS group, except for the CS exposure.

\section{Broncho-alveolar lavage (BAL)}

After the last CS exposure, mice were sacrificed under anesthesia. AM were obtained by BAL. Briefly; the lung was washed five times with $1 \mathrm{ml}$ phosphate-buffered saline (PBS). The recovered BAL fluids (BALF) were pooled. BAL cells were centrifuged at $185 \times \mathrm{g}$ for 10 minutes. The cell pellet was resuspended in $0.5 \mathrm{ml}$ of culture medium [RPMI 1640 (Nacalaitesque, Kyoto, Japan) containing 10\% fetal calf serum (FCS, Hyclone Laboratories, UT, USA), $100 \mathrm{U} / \mathrm{ml}$ penicillin (Meiji Seika, Tokyo, Japan) and $100 \mu \mathrm{g} / \mathrm{ml}$ streptomycin (Meiji Seika)]. A volume of $10 \mu \mathrm{l}$ of the cell suspension was mixed with $10 \mu \mathrm{l}$ of $0.2 \%$ trypan blue to determine total cell number and viability. The purity and viability of AM were more than $98 \%$ and $95 \%$, respectively.

\section{Plaque-forming cell (PFC) assay for antibody production}

To measure antibody production, CS and non-CS exposed mice were injected intravenously with sheep red blood cells (SRBC, $10^{8}$ cells/ mouse) as antigen for 4 days after which spleens from the mice were pressed through a stainless mesh in a plastic dish. Spleen cells in the plastic dish were washed with RPMI 1640, counted and suspended with culture medium. The PFC was determined with the method of Cunningham and Szenberg [18]. Briefly, spleen cell suspensions were mixed with 5\% SRBC and $2.5 \%$ of guinea pig serum and adjusted to a final volume of $500 \mu \mathrm{l}$ with culture medium. The cell suspension, from each mouse was injected into a Cunningham chamber that was sealed with paraffin wax and incubated at $37^{\circ} \mathrm{C}$ for 1 hour. Plaques were counted under a microscope, and the data was expressed as numbers of $\mathrm{PFC} / 10^{6}$ spleen cells. To measure the number of PFC at the induction phase of antibody production, mice were injected with SRBC $\left(10^{6}\right.$ cells/ mouse) and AM ( $10^{5}$ cells/mouse) at the same time. After 4 days of injection, antibody production was measured by PFC assay. To measure the number of $\mathrm{PFC}$ during the expression phase of antibody production, $\mathrm{AM}\left(2 \times 10^{5}\right.$ cells $\left./ \mathrm{ml}\right)$ were mixed with spleen cell suspensions and PFC assay was performed.

\section{Preparations of water-soluble cigarette extract (WSCE) or water soluble cigarette smoke (WSCS)}

For preparation of WSCE, dried leaf collected from 10 Cigarettes was extracted by water at $105^{\circ} \mathrm{C}$ for $1 \mathrm{~h}$. The water-soluble extract was centrifuged at $3000 \mathrm{rpm}$ for $30 \mathrm{~min}$ and was sterilized by $0.22 \mu \mathrm{m}$ filtration. For preparation of WSCS, CS generated from 20 cigarettes was bubbled through in water. The water-soluble extract was centrifuged at $3000 \mathrm{rpm}$ for $30 \mathrm{~min}$ and was sterilized by $0.22 \mu \mathrm{m}$ filtration.

\section{$B$ cell proliferation}

$B$ cell proliferation was analyzed by ${ }^{3} \mathrm{H}$-thymidine (NEF Life Science Products, MA, USA) incorporation. $5 \times 10^{5}$ spleen cells from normal mice were cultured in a final volume of $200 \mu \mathrm{l}$ with $10 \mu \mathrm{g} / \mathrm{ml}$ lipopolysaccharide (LPS, E.coli, O127:B8, Nacalaitesque, Kyoto, Japan) and various concentrations of WSCE or WSCS in 96-well flat-bottom culture plate (Becton Dickinson, MA, US). The cultures were incubated at $37^{\circ} \mathrm{C}$ under the presence of $5 \% \mathrm{CO}_{2}$. After $24 \mathrm{~h}$ cultured, they were pulsed with $18.5 \mathrm{kBq}$ of ${ }^{3} \mathrm{H}$-Thymidine for $24 \mathrm{~h}$ before harvesting. The cells were harvested onto filter paper, and radioactivity of incorporated ${ }^{3} \mathrm{H}$-thymidine was measured using liquid scintillation counter (Global Medical Instrumentation, MN, USA).

\section{Surface antigens expression}

AM were resuspended in Fluorescence Activated Cell Sorter (FACS) buffer (PBS containing $100 \mu \mathrm{g} / \mathrm{ml} \mathrm{CaCl} / \mathrm{MgCl}_{2}, 0.01 \%$ sodium azide and $1 \% \mathrm{FCS}$ ), and stained with $0.5 \mu \mathrm{g}$ of fluorescein isothiocyanate (FITC) or phycoerithrin (PE)-conjugated monoclonal antibodies $(\mathrm{mAb})$ at $4^{\circ} \mathrm{C}$ for 45 minutes. FITC-conjugated anti-CD80, anti-CD11b, anti$\mathrm{CD} 16 / 32$ and PE-conjugated anti-Class II $\mathrm{mAb}$ were obtained from BD. Bioscience. After incubation, AM were washed two times with FACS buffer and then resuspended in $300 \mu$ of FACS buffer. Ten thousand cells were acquired and gated appropriately using forward and side scatter plots. Surface antigens-positive cells were analyzed using FACS Calibur (Becton Dickinson, CA, USA).

\section{Phagocytic activity}

AM $\left(10^{5}\right.$ cells $\left./ 100 \mu \mathrm{l}\right)$ were mixed with FITC-labeled SRBC $\left(10^{6}\right.$ cells $/ 100 \mu \mathrm{l}$ ) and cultured at $37^{\circ} \mathrm{C}$ under the presence of $5 \% \mathrm{CO}_{2}$ for 2 hours. FITC-labeled SRBC were then hemolyzed by hypotonic lysis, and AM were centrifuged at $185 \times \mathrm{g}$ for 10 minutes and was resuspended in $300 \mu \mathrm{l}$ of FACS buffer. Five thousands cells were acquired and gated appropriately using forward and side scatter plots. Phagocytic cells were analyzed using FACS Calibur.

\section{Cytokine and NF- $\mathrm{kB}$ mRNA expression}

Aliquots of AM, obtained by BAL ( $10^{5}$ cells $/ 100 \mu \mathrm{l} /$ well $)$, were cultured with or without LPS or Zymosan (final concentration $10 \mu \mathrm{g} /$ $\mathrm{ml}$ ) in 96 -well flat bottom culture plates at $37^{\circ} \mathrm{C}$ under the presence of $5 \% \mathrm{CO}_{2}$. After 24 hours of culture, total RNA was isolated by the method of acid guanidinium thiocyanate-phenol-chloroform. Total RNA was transcribed to cDNA with MLV reverse transcriptase (Invitrogen, Carlsbad USA). Oligonucleotide primers were used from published cDNA sequences of IL-1 $\beta$ (250bp), TNF- $\alpha$ (253bp), NF- $\kappa B$ (283bp) and $\beta$-actin (268bp), which acted as a house-keeping gene. PCR was performed for 28 cycles against $\beta$-actin, 30 cycles against IL- $1 \beta$ and 32 cycles against TNF- $\alpha$ and NF- $\kappa B$ using the following primer pairs: $\beta$-actin sense (5'-GCATTGTTACCAACTGGGAC-3') and $\beta$-actin antisense (5'-TCTCCGGAGTCCATCACAAT-3'); IL- $1 \beta$ sense (5'-AGCTACCTGTGTCTTTCCCG-3') and IL- $1 \beta$ antisense (5'-GTCGTTGCTTGGTTCTCCTT-3'); TNF- $\alpha$ sense (5'-AGTGGTGCCAGCCGATGGGTTGT-3') and TNF- $\alpha$ antisense (5'-GCTGAGTTGGTCCCCCTTCTCCAG- $\left.3^{\prime}\right)$; NF- $\kappa$ B sense $\left(5^{\prime}\right.$-CTCCCTACGGTGGGATTACA-3') and NF- $\mathrm{kB}$ anti-sense (5'-AGCTGCAGAGCCTTCTCAAG- ${ }^{\prime}$ ). The amplification profile consisted of denaturation at $94^{\circ} \mathrm{C}$ for 30 seconds, primer annealing at $56^{\circ} \mathrm{C}$ for 30 seconds, and extension at $72^{\circ} \mathrm{C}$ for 30 seconds. PCR products were visualized using ethidium bromide after $8 \%$ polyacrylamide gel electrophoresis. Cytokine and NF- $\mathrm{kB}$ mRNA expression was quantified by Scion imaging.

\section{Statistical analysis}

All values were expressed as mean \pm standard deviation (S.D.). Statistical significance was assessed using Student's $t$ test. Any p-value less than 0.05 was considered significant. 


\section{Results}

\section{CS increase AM number and size in BALF}

The number of AM was significantly $(\mathrm{p}<0.001)$ increased in CSexposed mice $\left(2.58 \pm 0.95 \times 10^{5}\right.$ cells/mouse) compared with non-CS exposed mice $\left(1.25 \pm 0.39 \times 10^{5}\right.$ cells/mouse) (Figure 1$)$. Both FSC and SSC values were increased in CS exposed mice compared with non-CS exposed mice. These results show that the size of AM became big and the internal cell structures were caused to complex.

\section{CS decreases PFC number at the induction phase of antibody production}

To investigate whether CS affects antibody production, spleen cells from CS exposed mice and non-CS exposed mice immunized with SRBC were measured by PFC assay. The number of PFC was significantly $(\mathrm{p}<0.01)$ decreased in CS exposed mice $\left(1103 \pm 359 / 10^{6}\right.$ spleen cells) compared with non-CS exposed mice $\left(1660 \pm 273 / 10^{6}\right.$ spleen cells) (Figure 2a). Since antibody production has been reported to be inhibited by CS, we investigated the effect of CS exposure on AM at induction and expression phases of antibody production. The number of PFC at the induction phase was significantly $(\mathrm{p}<0.01)$ decreased in CS exposed mice $\left(211 \pm 86 / 10^{6}\right.$ spleen cells) compared with non-CS exposed mice ( $387 \pm 75 / 10^{6}$ spleen cells) (Figure $2 \mathrm{~b}$ ). However, the number of PFC at the expression phase was not different between CS exposed mice $\left(1883 \pm 520 / 10^{6}\right.$ spleen cells) and non-CS exposed mice $\left(1800 \pm 473 / 10^{6}\right.$ spleen cells) (Figure 2c).

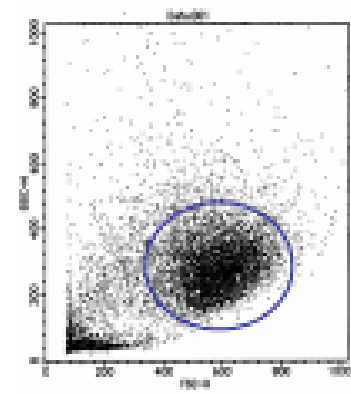

NSM

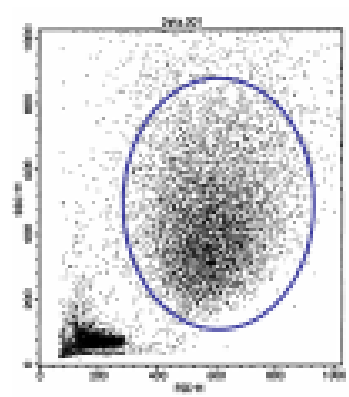

SM

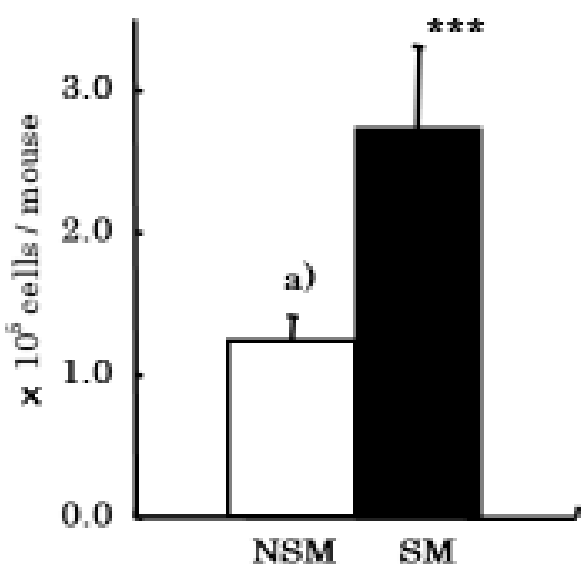

NSM

SM

Figure 1. Effects of CS on the number and Dot plot of AM in BALF. After CS exposure, mice were sacrificed. AM was obtained from brocho-alveolar lavage fluid (BALF). Total number and viability of AM were determined by trypan blue dye exclusion test. Dot plots of AM were analyzed by FACS. NSM: Non-smoke exposed mice, SM: Smoke exposed mice. a) mean \pm S.D. Statistical significance was assessed using Student's $t$ test. *** $<<0.001$ compared with NSM

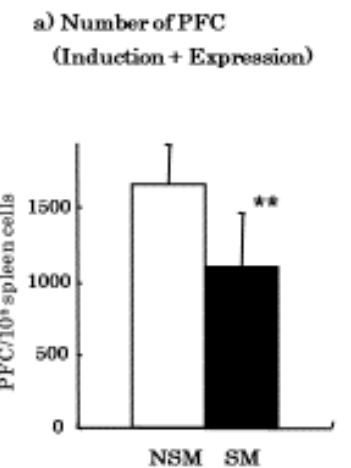

b) Induction phase

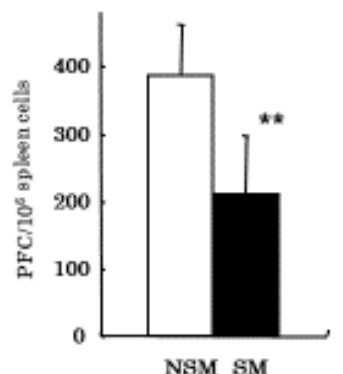

c) Expresaion phase

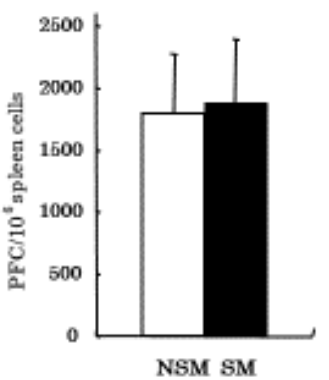

Figure 2. Effects of CS on antibody production. Antibody production was assayed by PFC assay. a) PFC assay was performed on day 4 after immunization with SRBC antigen. b) Induction phase; mice were injected with SRBC $\left(10^{6}\right.$ cells/mouse $)$ and AM $\left(10^{5}\right.$ cells/mouse $)$ at the same time. After 4 days injection, antibody production was assayed by PFC assay. c) Expression phase; AM $\left(2 \times 10^{5}\right.$ cells $\left./ \mathrm{ml}\right)$ were mixed with spleen cell suspensions and PFC assay were performed. NSM: Non-smoke exposed mice, SM: Smoke exposed mice. $* *$ p $<0.01$ compared with NSM 


\section{WSCE or WSCS decreases B cell proliferation}

Because CS did not affect mature B cells at the expression phase of antibody production, we investigated the effect of WSCE or WSCS on immature B cell proliferation stimulated with LPS. We found that B cell proliferation was decreased in a dose dependent manner with WSCE or WSCS treatment (Figure 3).

\section{CS decreases expression of surface antigens}

Since CS inhibited antibody production, we next investigated the effect of CS on the expression of surface antigens associated with antigen presentation. The percentage of Class II or B7.1 antigens positive cells was significantly $(\mathrm{p}<0.001)$ decreased in CS exposed mice $(31.35 \pm 3.63$ and $52.22 \pm 7.42$, respectively) compared with non-CS exposed mice $(53.28 \pm 4.98$ and $85.63 \pm 2.68$, respectively) (Figure 4 ).

\section{CS decreases phagocytic activity of AM}

Since CS affected the induction phase of antibody production and decreased the expression of surface antigens associated with antigen presentation, we decided to investigate how CS affected the phagocytic activity of AM for antigen. The percentage of phagocytic activity of AM was significantly $(\mathrm{p}<0.001)$ decreased in CS exposed mice $(20.86 \pm 4.75)$ compared with non-CS exposed mice ( $40.35 \pm 4.85)$ (Figure 5). Surface antigens associated with phagocytosis on AM were also studied. The percentage of CD11b antigen positive cells was significantly $(\mathrm{p}<0.001)$ decreased in CS exposed mice $(20.53 \pm 3.21)$ compared with non-CS exposed mice ( $57.53 \pm 14.95)$ (Figure $5 \mathrm{~d}$ ). However, the percentage of CD16/32 antigen positive cells was not different between CS exposed mice $(81.79 \pm 6.87)$ and non-CS exposed mice $(91.23 \pm 7.17)$ (Figure $5 d)$.

\section{CS decreases expression of cytokine and NF- $\mathrm{B}$ mRNA}

To determine whether CS affects the mRNA expression of cytokines associated with lymphocyte and macrophage activation, IL$1 \beta$ and TNF- $\alpha$ mRNA was analyzed by RT-PCR. With LPS stimulation, the ratio of IL- $1 \beta$ mRNA expression (IL- $1 \beta / \beta$-actin) in AM was significantly $(\mathrm{p}<0.001)$ decreased in CS exposed mice $(0.36 \pm 0.09)$ compared with non-CS exposed mice $(0.66 \pm 0.12)$ (Figure $6 a)$. In Zymosan stimulation, the ratio of TNF- $\alpha$ mRNA expression (TNF- $\alpha / \beta-$ actin) in AM was also significantly $(\mathrm{p}<0.05)$ decreased in CS exposed mice $(1.25 \pm 0.56)$ compared with non-CS exposed mice $(2.14 \pm 0.62)$ (Figure 6b).

Since both IL- $1 \beta$ and TNF- $\alpha$ mRNA was decreased in AM following CS exposure, we investigated the expression of NF- $\kappa B$ mRNA, which is associated with cytokine gene activation. In Zymosan stimulation, the ratio of NF- $\kappa \mathrm{B}$ mRNA expression (NF- $\kappa \mathrm{B} / \beta$-actin) in $\mathrm{AM}$ was significantly $(\mathrm{p}<0.001)$ decreased in CS exposed mice $(0.50 \pm 0.15)$ compared with non-CS exposed mice $(1.07 \pm 0.19)$ (Figure $6 \mathrm{c}$ ).

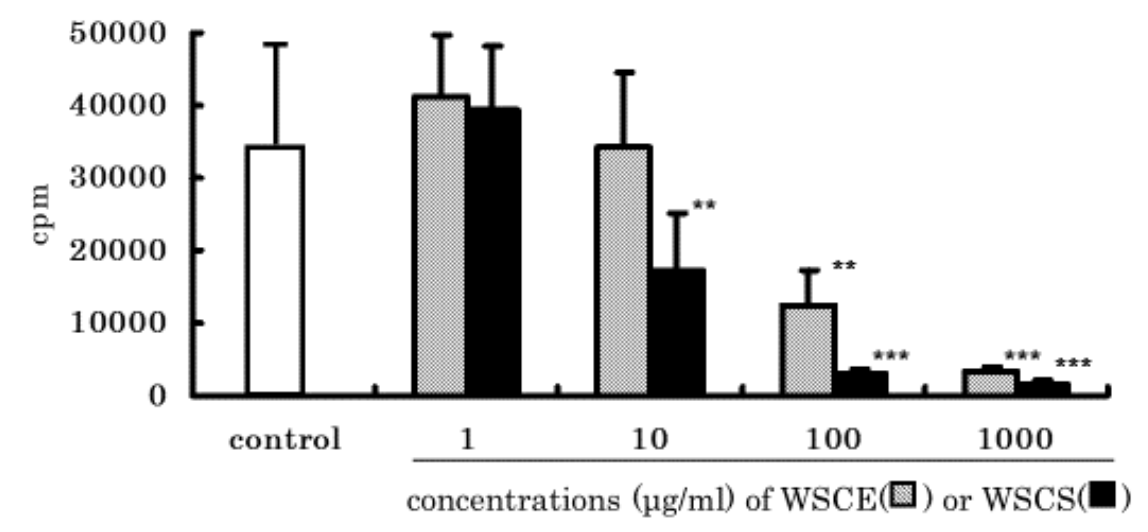

Figure 3. Effects of WSCE and WSCS on B cell proliferation. Spleen cells were co-cultured with LPS (10 $\mu \mathrm{g} / \mathrm{ml})$ and WSTE or WSTS. After 24 hours of culture, cell proliferation was analyzed by ${ }^{3} \mathrm{H}$-thymidine incorporation. ${ }^{* *} \mathrm{p}<0.01, * * * \mathrm{p}<0.001$ compared with control

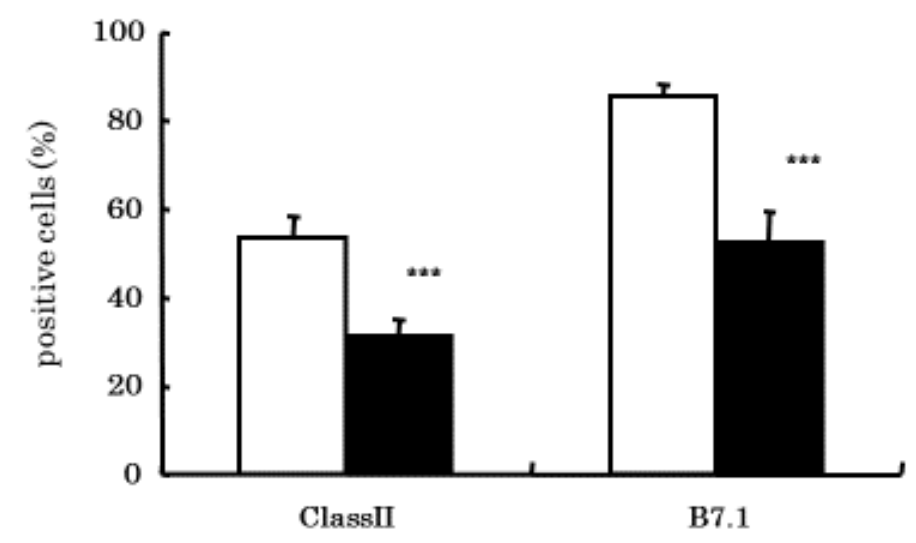

Figure 4. Effects of CS on expressions of surface antigens. Expressions of surface antigens associated with antigen presentation on AM were analyzed by FACS using monoclonal antibodies. $\square$ : NSM (Non-smoke exposed mice), $\mathbf{m}$ : SM (Smoke exposed mice). ${ }^{* * *}<0.001$ compared with NSM 


\section{a) NSM}

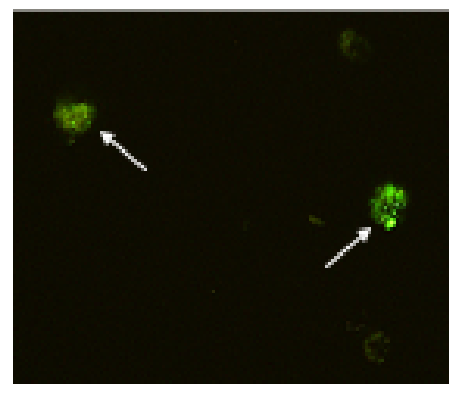

b) SM

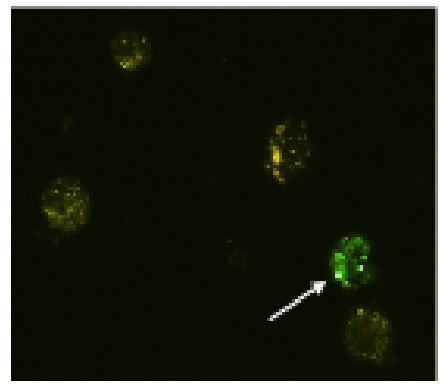

c) Phagocytic activity

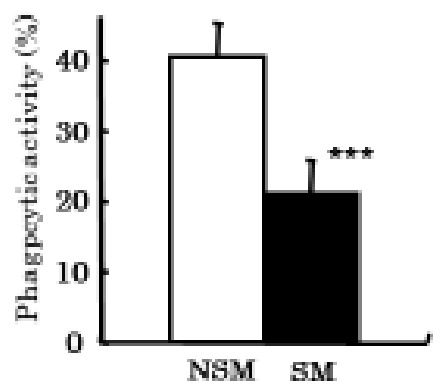

d)Phagocytic receptor

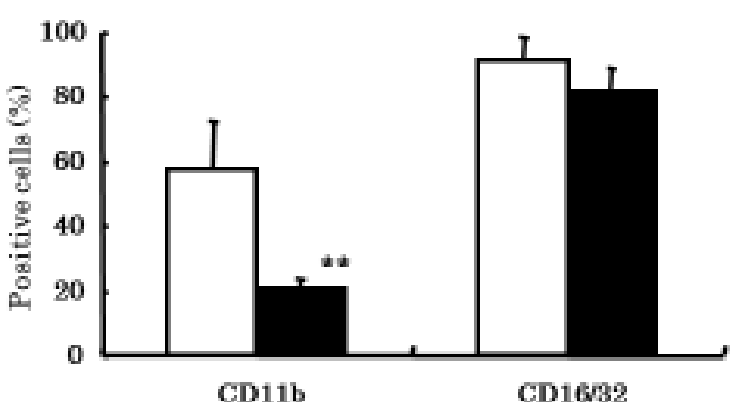

Figure 5. Effects of CS on phagocytic activity. a) Phagocytosis of FITC-labeled SRBC was observed in AM from non-CS exposed mice. b) Phagocytosis of FITC-labeled SRBC was observed in AM from CS exposed mice. c) Phagocytic activity was analyzed by FACS using FITC-labeled SRBC. d) Expressions of surface antigens on AM associated with phagocytosis on AM were analyzed by FACS using monoclonal antibodies. $\square$ : NSM (Non-smoke exposed mice), $\mathbf{\square}$ : SM (Smoke exposed mice). **p<0.01, ***p<0.001 compared with NSM

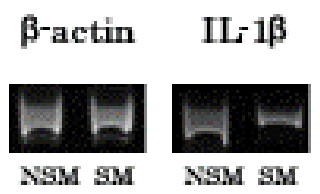

a) $\mathrm{IL}-1 \beta$

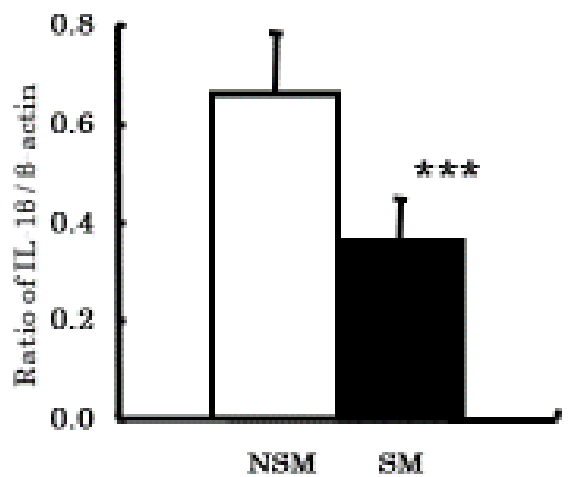

$\beta$-actin TNFa

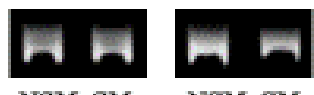

NSM SM NSM SM $\beta$-actin NF-kB

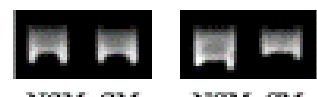

NSM SM NSM SM b) TNF- $\alpha$

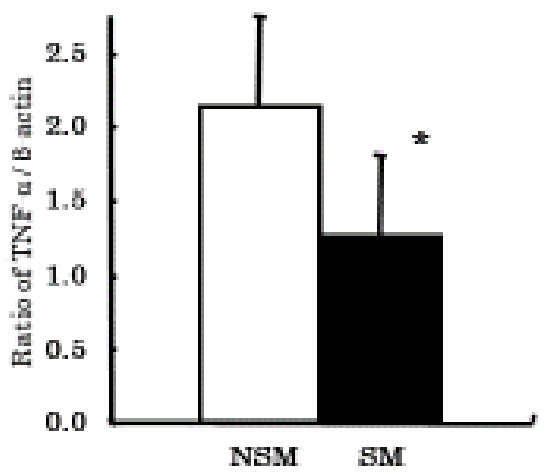

c) NF-KB

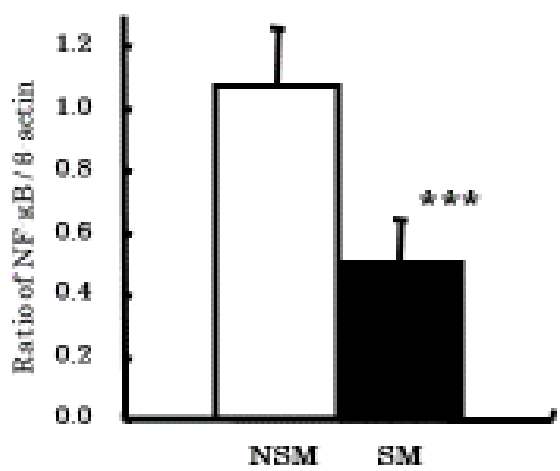

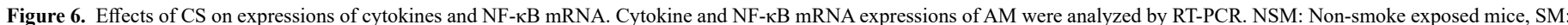
Smoke exposed mice. *: $\mathrm{p}<0.05, * * *: \mathrm{p}<0.001$ compared with NSM 


\section{Discussion}

In the alveoli, AM play an important role in the lung's immune system. The primary functions of AM are phagocytosis; productions of cytokines, enzymes and reactive oxygen intermediates; and antigen presentation $[8,9]$. CS includes approximately 6,000 kinds of chemical substances, and 200 of these chemicals are toxic substances [2,3]. CS has both a gas phase and a particle phase and is inhaled into the lung during cigarette smoking. AM recognized and incorporated the foreign substances of CS when the reach the gas - exchange area of the lung. Therefore, CS may negatively affect AM functions and immune response.

The number of AM was significantly increased in CS exposed mice compared with non-CS exposed mice and may be due to CS inducing translocation of immature monocytes from peripheral blood to alveoli. Besides the present study, there are a number of reports of CS increasing the number of AM in humans and animals $[10,19]$.

Both FSC and SSC values were increased in CS exposed mice compared with non-CS exposed mice, which indicates that CS caused AM to increase in size with corresponding enlargement of internal cell structures. These alterations may be due to AM intake of CS particles. There are previous reports of cellular ultrastructural changes in AM from smokers $[20,21]$.

To determine whether CS affects antibody production, spleen cells from CS exposed mice and non-CS exposed mice immunized with SRBC were measured by PFC assay. The number of PFC was significantly decreased in CS exposed mice compared with nonCS exposed mice. Our findings confirm previous reports of the PFC response being inhibited in mice and rats by CS exposure $[11,12]$. These results agree with our present report of decreased antibody production. However, there is a one study that reported an increased PFC response in mice exposed to CS [10]. The discrepancy between that study and ours may be different experimental systems. Currently, there is no consensus on the effects of CS exposure on IgG, IgA and IgM antibody serum concentration $[7,22,23]$.

Since antibody production was inhibited by CS exposure, we focused on the induction and expression phases of antibody production in AM. The number of PFC at the induction phase was significantly decreased in CS exposed mice compared with non-CS exposed mice. However, the number of PFC at the expression phase was not different between CS exposed mice and non-CS exposed mice. These results suggest that cigarette smoking impact early, but not late, stages of antibody production.

CS did not affect mature B cells at the expression phase of antibody production. Therefore, we investigated the effect of WSCE and WSCS on immature B cell proliferation stimulated with LPS. B cell proliferation was decreased in a dose dependent manner with WSCE or WSCS treatment. It has been reported that smokeless tobacco and tobacco glycoprotein (TGP) activates B cell proliferation in humans and mice [4], and these results differ with the inhibition of B cell proliferation seen in our present study. The discrepancy in results may be due to different methods of cigarette extraction.

Since antibody production was inhibited by CS exposure, we also investigated the effect of CS on expression of surface antigens associated with antigen presentation. Class II antigen is expressed by antigen presenting cells, which in turn, present foreign antigens to T cells. B7.1 is a co-stimulatory molecule for antigen presentation and binds CD28 on T cells. The percentage of Class II and B7.1 antigen positive cells were significantly decreased in CS exposed mice compared with non-CS exposed mice. These results suggest that reduced expression of surface antigens associated with antigen presentation induces the suppression of antigen presentation to T cells and T cell activation. Decreased Class II and B7.1 antigen positive cells have been found in humans and mice exposed to CS $[17,24,25]$.

Since CS affected an early phase of antibody production and expression of surface antigens associated with antigen presentation, we investigated the effect of CS on phagocytic activity of AM for antigen. The percentage of phagocytic activity of AM was significantly decreased in CS exposed mice compared with non-CS exposed mice. The inhibition of phagocytosis in AM may be due to CS particles saturating the normal phagocytic ability of AM. There are reports that AM from CS exposed mice had inhibited phagocytosis to C.albicans and latex beads [26,27]. These results agree with the phagocytic activity seen in our present report. Surface antigens associated with phagocytosis on AM were also investigated. $\mathrm{CD} 11 \mathrm{~b}$ is a receptor for $\mathrm{C} 3 \mathrm{~b}$ complement, and CD16/32 is a receptor for Fc of IgG. These surface receptors assist phagocytosis by $\mathrm{AM}$ by acting as an opsonin. The percentage of CD11b antigen positive cells was significantly decreased in CS exposed mice compared with non-CS exposed mice. However, the percentage of CD16/32 antigen positive cells was not different between CS exposed mice and non-CS exposed mice. These results suggest that the inhibition of phagocytic activity by CS was caused by the inhibition of CD11b surface antigen and corresponding decreased $\mathrm{C} 3 \mathrm{~b}$ complement receptor activity. Decreased CD11b antigen positive cells from CS exposed mice have previously been reported [19].

To investigate whether CS affects mRNA expression of cytokines associated with lymphocyte and macrophage activation, IL-1 $\beta$ and TNF- $\alpha$ mRNA expression were analyzed by RT-PCR. IL- $1 \beta$ and TNF- $\alpha$ are associated with activation of AM functions and lymphocyte proliferation. With LPS stimulation, the ratio of IL-1 $\beta$ mRNA expression (IL- $1 \beta / \beta$-actin) in AM was significantly decreased in CSexposed mice compared with non-CS exposed mice. In Zymosan stimulation, the ratio of TNF- $\alpha$ mRNA expression (TNF- $\alpha / \beta$-actin) in AM was also significantly decreased in CS exposed mice compared with non-CS exposed mice. Similar results (decreased production of IL-1 $\beta$ and TNF- $\alpha$ ) have been reported for AM from smokers [28-30].

Since mRNA expression of IL- $1 \beta$ and TNF- $\alpha$ was decreased by CS exposure, we focused on NF- $\kappa B$ mRNA expression. NF- $\kappa B$ is the major transcription factor that regulates the expression of various cytokine genes [31]. In Zymosan stimulation, the ratio of NF- $\kappa B$ mRNA expression (NF- $\kappa \mathrm{B} / \beta$-actin) in AM was significantly decreased in CS exposed mice compared with non-CS exposed mice. It has been reported that NF- $\kappa B$ activity and mRNA expression of the same cytokines studied in our study were suppressed in monkey lung tissues following environmental tobacco smoke (ETS) exposure [32]. However, there are reports that ETS and nicotine exposure lead to increased NF$\kappa \mathrm{B}$ mRNA expression in human oral keratinocytes [33,34], and these results differ from the NF- $\kappa B$ mRNA expression seen in our study. IL$1 \beta$ and TNF- $\alpha$ mRNA expression may be inhibited by CS suppressing $\mathrm{NF}-\kappa \mathrm{B}$.

In conclusion, the results from this study suggest inhibition of antibody production by cigarette smoking is caused in the following manner in AM: 1) inhibition of phagocytosis and 2) expression of surface antigen associated with antigen presentation. A possible consequence of these changes is an increased risk for bacterial and virus infections. 


\section{Conclusion}

These results suggest that the inhibition of antibody production by cigarette smoke is caused by the inhibition of phagocytosis and expression of surface antigens associated with antigen presentation. Such inhibition of AM functions may increase the risk of bacterial and virus infections such as COVID-19.

\section{Conflicts of interest}

The authors declare no conflict of interest, financial or otherwise.

\section{Acknowledgements}

The authors acknowledge Dr. Suzette Smiley-Jewell for assisting with manuscript preparation.

\section{References}

1. Burns MD (1991) Cigarettes and cigarette smoking. Clin Chest Med 12: 631-642. [Crossref]

2. Johnson DJ, Houchens PD, Kluwe MW and Fisher LG (1990) Effects of mainstream and environmental tobacco smoke on the immune system in animals and humans: a review. Clit Rev Toxicol 20: 369-395.

3. Rawbone GR (1987) The measurement of environmental tobacco smoke particulates. Toxicology Letters 35: 125-129.

4. Takeuchi M (2001) Smoking and immune functions. Clinical Immunology 36: 843-850.

5. Barbour ES (1997) Tobacco and smoking: Environmental factors that modify the host response (Immune system) and have an Impact on periodontal health. Crit Rev Oral Biol Med 8: 437-460.

6. Centers for Disease Control (CDC) (1989) The Surgeon general's 1989 report on reducing the health consequences of smoking: 25 years of progress. MMWR Morb Mortal Wkly Rep 38: 1-32.

7. Goud N, Kaplan M, Subbarao B (1992) Effects of cigarette smoke on the antibody responses to thymic independent antigens from different lymphoid tissues of mice. Arch Toxicol 66: 164-169. [Crossref]

8. Fels A and Cohn AZ (1986) The alveolar macrophage. J Appl Physiol 60: 353-369.

9. Sopori M (2002) Effects of cigarette smoke on the immune system. Nat Rev Immunol 2: $372-377$.

10. Nakata A, Tanigawa T, Araki S, Sakurai S, Iso H, et al. (2004) Lymphocyte Subpopulations among Passive Smokers. Journal of American Medical Association (JAMA) 291: 1699-1700.

11. Kalra R, Singh P, Savage M, Finch L, Sopori M (2000) Effects of cigarette smoke on immune response: chronic exposure to cigarette smoke impairs antigen-mediated signaling in T cells and depletes IP3-sensitive Ca2+ stores. J Pharmacol Exp Ther 293: 166-171.

12. Sopori M (1989) Cigarette smoke causes inhibition of the immune response to intratracheally administered antigens. Toxicol Appl Pharmacol 97: 489-499. [Crossref]

13. Takeuchi M (1982) Studies on the immunomodulation of Propionibacteriumacnes in mice. Japanese Journal of Allergology 31: 381-389.

14. Takeuchi M, Asada H and Nagai S (2005) Effect of tobacco smoking on antigen presenting activity in alveolar macrophage. Clinical Immunology 44: 546-550.

15. Takeuchi M, Nagai S, Izumi T (1988) Effect of smoking on natural killer cell activity in the lung. Chest 94 : 688-693.
16. Takeuchi M (2001) Inhibition of lung natural killer cell activity by smoking: the role of alveolar macrophages. Respiration 68: 262-267.

17. Takeuchi M (2000) Effect of smoking on immunological functions of alveolar macrophages in mice. Tobacco Counters Health WATCH 2000 (A.K.Varma ed) Macmilan Ltd, pp: 168-171.

18. Cunningham AJ and Szenberg A (1968) Further improvements in plaque technique for detecting single antibody-forming cells. Immunology 14: 599-601.

19. Löfdahl M, Wahlström J, Sköld M (2006) Different inflammatory cell pattern and macrophage phenotype in chronic obstructive pulmonary disease patients, smokers and non-smokers. Clin Exp Immunol 145: 428-437.

20. Polosukhin V (2001) Ultrastructural heterogeneity of the alveolar macrophages from tobacco smokers with chronic bronchitis. Ultrastruct Pathol 25: 5-11.

21. Pratt A (1971) The ultrastructure of alveolar macrophages from human cigarette smokers and nonsmokers. Lab Invest 24: 331-338. [Crossref]

22. Okazaki N (1991) The suppressive effects of smoking on antibody production in experimental hypersensitivity pneumonitis in rabbits. Nihon Kyobu Shikkan Gakkai Zasshi 29: 943-953.

23. Sopori M (1998) Effect of nicotine on the immune system: possible regulation of immune responses by central and peripheral mechanisms. Psychoneuroendocrinology 23: 189-204.

24. Robbins S (2004) Cigarette smoke decreases pulmonary dendritic cells and impacts antiviral immune responsiveness. Am J Respir Cell Mol Biol 30: 202-211.

25. Vassallo R (2005) Cigarette smoke extract suppresses human dendritic cell function leading to preferential induction of Th-2 priming. J Immunol 175: 2684-2691.

26. Ortega E, Barriga C, Rodriguez A (1994) Decline in the phagocytic function of alveolar macrophages from mice exposed to cigarette smoke. Comp Immun Microbiol Infect Dis 17: 77-84.

27. Ortega E, Hueso F, Collazos E, Pedrera I, Barriga C, Rodríguez B (1992) Phagocytosis of latex beads by alveolar macrophages from mice exposed to cigarette smoke. Comp Immunol Microbiol Infect Dis 15: 137-142.

28. Chen H, Cowan J, Hasday D, Vogel N (2007) Tobacco smoking inhibits expression of proinflammatory cytokines and activation of IL-1R-associated kinase, p38, and NFkappaB in alveolar macrophages stimulated with TLR2 and TLR4 agonists. J Immunol 179: 6097-6106.

29. Nagai S (1991) IL-1 and IL-1 inhibitory activity in the culture supernatants of alveolar macrophages from patients with interstitial lung diseases. Chest 99: 674-680.

30. Proulx L (2007) Alveolar macrophage cytotoxic activity is inhibited by 4-(methylnitrosamino)-1-(3-pyridyl)-1-butanone (NNK), a carcinogenic component of cigarette smoke. Cancer Immunol Immunother 56: 831-838.

31. Vlahos R, Bozinovski S, Jones E, Powell J, Gras J, et al. (2006) Differential protease, innate immunity, and NF-kappaB induction profiles during lung inflammation induced by subchronic cigarette smoke exposure in mice. Am J Physiol Lung Cell Mol Physiol 290: L931-945. [Crossref]

32. Zhong Y, Zhou M, Joad P, Pinkerton K (2006) Environmental tobacco smoke suppresses nuclear factor-kappaB signaling to increase apoptosis in infant monkey lungs. $\mathrm{Am} \mathrm{J}$ Respir Crit Care Med. 174: 428-436. [Crossref]

33. Arredondo J (2007) Receptor-mediated tobacco toxicity: alterations of the NF-kappaB expression and activity downstream of alpha7 nicotinic receptor in oral keratinocytes. Life Sci 80: 2191-2194. [Crossref]

34. Arredondo J (2006) Receptor-mediated tobacco toxicity: cooperation of the Ras/Raf-1/ MEK1/ERK and JAK-2/STAT-3 pathways downstream of alpha7 nicotinic receptor in oral keratinocytes. FASEB J 20: 2093-2101.

Copyright: (C2020 Kobayashi K. This is an open-access article distributed under the terms of the Creative Commons Attribution License, which permits unrestricted use, distribution, and reproduction in any medium, provided the original author and source are credited. 